\title{
Social determinants of rest deprivation amongst Ghanaian women: national and urban-rural comparisons with data from a cross-sectional nationally representative survey
}

Maurice B Mittelmark, Torill Bull

\begin{abstract}
Background: Rest deprivation (rest/napping/sleep 6 or less hours daily) is a clinically recognised risk factor for poor health, but its epidemiology is little studied. This study reports prevalence's and social correlates of rest deprivation in Ghana.

Methods: Data are from the 2008 Ghana Demographic and Health Survey. Women ages 15-49 were recruited in a national sampling design. Respondents were 4,916 women in the national sample, a sub-sample of 530 women in the three northernmost rural regions and a sub-sample of 853 women in urban Greater Accra.

Results: Prevalence's of rest deprivation were $0.13 \%$ nationally, 14.5\% in Greater Accra and $16.8 \%$ in the North. The significant correlates nationally were age, education, wealth index, Christian religion and literacy. In Accra, they were age, wealth index, having household electricity, and possession of a refrigerator, a stove and a mobile phone. In the North, they were education, occupation, drinking water source, possession of motorcycle/scooter, Christian religion, literacy, and possession of a clock and a cupboard. In logistic regression analyses controlling for age in the national sample, the significant odds ratios were 1.40 for no education compared to secondary and higher education, $0.78-0.43$ for the four poorer wealth quintiles compared to the richest wealth index quintile, and 0.55 for Christian religion compared to all others.

Also controlling for age, the significant odds ratios in Accra were 2.15 for the second richest wealth quintile compared to the richest quintile and 0.16 for possession of a mobile phone. In the North they were 0.49 for Christian religion compared to all others, 1.87 for having a protected compared to an unprotected water source, and 0.41 for having a cupboard in the home.

Conclusions: Education, wealth and religion were related to rest deprivation nationally but not in the urban and rural regions (except for religion in the North). This suggests caution in generalising about the social correlates of rest deprivation at a regional level, based on national-level data. Qualitative research in local contexts is needed in order to illuminate the social determinants of rest pattern, and to provide guidance about better ways to measure such determinants in future survey research.
\end{abstract}

\section{Background}

The terms short sleep duration, sleep insufficiency and sleep restriction are synonymous concepts described in the medical and public health literatures, all referring to inadequate quantities of daily, contiguous sleep. Many

\footnotetext{
* Correspondence: Maurice.mittelmark@uib.no

Department of Health Promotion and Development, Faculty of Psychology, University of Bergen, Christiesgt. 13, 5020 Bergen, Norway
}

studies show that the optimal sleep duration is 7-8 hours [1-3], with negative mental and physical health effects at sleep durations both below and above this optimal level [1,2,4-10]. There is a long line of evidence from laboratory research that adequate sleep is essential to good immune functioning [11,12], and this may help explain the wide range of health problems that are associated with poor sleep. However, the evidence on the 
association of poor sleep and poor health and functioning is not entirely consistent. For example, subjective wellbeing has been observed both to vary $[13,14]$ and not to vary with sleep duration [15], and the same is true for mortality $[16,17]$.

Compared to the clinical evidence on sleep and health, the epidemiology of sleep and health is relatively unexplored. Few population-based studies provide prevalence estimates and assess putative risk factors for sleep insufficiency. Of those that are in the literature, one by Soldatos [18] provides international comparisons. In data from 11 countries, the highest rate of sleep insufficiency was reported in Belgium (23.2\%) and the lowest rate was in Austria (10.4\%), indicating a high level of heterogeneity. Athens Insomnia Scale [18] ratings showed significant age differences with older respondents reporting higher levels of night awakenings, waking earlier than desired, less total sleep duration and less sleepiness during the day [19]. Another international study observed that higher wages were associated with lower sleep time for men but not for women and the (non-significant) trend for women was the reverse of that for men [20].

At the national level, in 2002 data from the USA's Behavioral Risk Factor Surveillance System (BRSS), 26\% of adults reported sleep insufficiency during 14 or more of the past 30 days [14]. In the same study, the prevalence of sleep insufficiency was significantly lower with age, higher for women, slightly higher with higher education, and higher for never married respondents and for those not able to work. The findings for age seem at odds with the findings of Soldatos, et al., [18], but that is not necessarily so, since the Soldatos, et. al. [18] study queried respondents about sleep patterns but not about self-perceived sleep sufficiency. Older people may experience less contiguous sleep than younger people experience, yet judge that their sleep is not problematic. In the 2002 BRSS, sleep insufficiency was significantly associated with poor self-reported health, physical and mental distress, depression and anxiety symptoms, pain and activity limitations.

In USA data from the 2001 Sleep in America Poll's nationally representative sample, significant correlations ranging from 0.24 to 0.51 were observed among five sleep problems: difficulty falling asleep, waking too early, daytime sleepiness, waking during the night and awaking unrefreshed [3]. In a nationally representative study in Britain in 1997, 58\% reported sleep problems one or more nights the previous week and 18\% reported sleep insufficiency the majority of nights [13]. In the same study, older people reported sleeping less, women reported more sleep problems, and quality of life was diminished for those sleeping short and long hours.

The most recent large-scale survey of sleep is from the 2006 BRSS [21]. Importantly, this was the first public health research project to recognise the importance to health and functioning of other forms of rest than nighttime sleeping. In many parts of the world, daily naps are an important component of restorative activity, as is the ability to take sufficient pauses from work. Regarding napping, one international study observed an overall napping prevalence of $23.1 \%$ and prevalence ranged from a high of $42.4 \%$ in Brazil to a low of $12 \%$ in Japan [19]. In the 2006 BRSS, respondents were asked "During the past 30 days, for about how many days have you felt you did not get enough rest or sleep?" In the combined data from four US states, insufficient rest or sleep during the previous 14 days was reported by $24.9 \%$ of respondents [21]. In the same data, the prevalence of rest/sleep problems was lower with age, higher for women, highest amongst those unable to work and higher amongst those with higher education levels.

\section{Living conditions}

While education and employment have been examined for associations with sleep insufficiency in some studies, very few have also examined income/expenditure/ wealth, which is the de rigueur indicator of social living conditions. The importance of living conditions to health has received greatly increased attention recently, with the issuance in 2008 of the World Health Organisation Commission on the Social Determinants of Health report "Closing the Gap in a Generation: Health Equity Through Action on the Social Determinants of Health [22]. The report emphasises the health inequities experienced by women, and amongst its major recommendations the report calls for civil society, governments, and global institutions to "Improve the well-being of girls and women and the circumstances in which their children are born, [...] improve living and working conditions and create social protection policy supportive for all..."

The only study reviewed above to examine the relationship of sleep insufficiency to income as well as education was an international economics study in which higher wages were associated with lower sleep time for men but not for women and the (non-significant) trend for women was the reverse of that for men [20]. The Alameda County Health and Ways of Living Study (California, USA) also examined the relationship of living conditions indicators and sleep insufficiency [9]. The age-adjusted odds of short sleep duration was 1.62 (CI 1.34-1.94) for respondents in the lowest household income quintile compared to the highest quintile, and the odds of short sleep duration were 1.51 for respondents with less than a high school education, compared to better educated respondents. We are aware of no other community-based study that has examined the association of sleep quantity with living conditions. Only 
the 2006 BRSS has examined rest and sleep sufficiency, but that study did not include a measure of income [21].

The studies referred to above are part of a very large literature extending back more than four decades, showing that too little rest is a risk factor for poor health. However, there are some gaps in the literature, including four that this paper focuses on.

The first is that the known social determinants of health generally - income, education and occupation amongst other indicators of living conditions - have hardly been examined in sleep research. A second gap is the paucity of data from the Global South. Most sleep studies are from a few industrialised countries that enjoy the highest socioeconomic status in the world, findings from which may generalise poorly to the Global South [23]. Third, sleep is but one aspect of regenerative health; rest and napping in combination with adequate sleep (and adequate physical activity, water intake and diet) are essential to healthy functioning. However almost nothing is known about patterns of rest including sleeping, but also relaxing and napping. Finally, national-level public sleep health studies may mask important regional differences, and regional-level analyses may be required to inform local policy and practice. A large degree of international variation was described above, and the 2006 BRSS suggests the same for regional variation. In those data from four US states, insufficient rest or sleep 14 or more days out of 30 was reported by a low of $20.8 \%$ of respondents in Delaware and a high of $27.4 \%$ of respondents in Rhode Island, two states that are not otherwise conspicuously different [21]. If prevalence rates vary regionally, and if living conditions are associated with sleep sufficiency, then varying living conditions in regions may explain part of the variation in sleep sufficiency. This is an empirical issue, which can only be approached with regional-level analyses.

This study aimed to investigate the prevalence of rest deprivation (6 and less hours daily of combined rest, napping and sleep) amongst Ghanaian women nationally and in two regions, the urban capital area of Greater Accra and the mostly rural regions Upper East, Upper West and the Northern region (referred to collectively hereafter as North). We investigated also the degree to which the living conditions of the women were related to rest deprivation. Living conditions were conceptualised and measured in the standard way for research in developing countries; the key indicators are ownership of material goods and housing quality (wealth index) and levels of education and occupation. Wealth replaces income, which is used in research in the Global North, since livelihoods in the Global South are typically a mix of activities, only some of which may generate income. Barter, trade and labour exchange are important elements in livelihood generation in developing countries. In addition to the three key living conditions indicators, the relationship of rest deprivation to a wide range of other living conditions indicators was examined in this exploratory study, including religion, literacy and land and livestock ownership.

\section{Methods}

This article reports analyses using data from the 2008 Ghana Demographic and Health Survey (GDHS) [24]. The survey collected data on housing and household characteristics, education, maternal health and child health, nutrition, family planning, gender, and knowledge and behaviour related to HIV/AIDS, living conditions, and combined hours of daily rest, napping and sleep. The 2008 GDHS was conducted by the Statistical Service of Ghana and the Ministry of Health/Ghana Health Service. Required ethical clearances were obtained by the Statistical Service of Ghana from the Ghana Health Service Ethical Review Committee in Accra, Ghana. Informed consent for the survey was obtained from the respondent at the beginning of the data collection interviews.

\section{Context}

Even if the last decades have brought some economic development to Ghana, the country is still one of the poorest in the world. In 2009, it ranked as number 152 of 182 countries on the Human Development Index [25]. Fifty-four percent of the population live in rural areas, the life expectancy is 57 years at birth, there is a high under-five mortality (112 per 1000), and a high maternal mortality (214 per 100000 live births [26]. Ghana is divided into ten political regions. An important characteristic of Ghana is the strong divide when it comes to level of development between the lush south of the country and the poorer, arid and less developed north. Administration and business is located in the south.

\section{Study design}

The 2008 GDHS had a two-stage stratified sampling design [24]. The sample units were 412 geographical clusters producing a national and regional representative sample with proportional representation of rural and urban populations. At the second stage of sampling, households were selected within each cluster after a complete household enumeration. The objective was the achievement of representative samples at urban-rural, regional and national levels, large enough to allow for precise estimates of key indicators. To adjust for nonresponses at all levels and for the stratified sampling design, sample weights were calculated. 12,360 households were selected. In half of these households all women aged 15-49 were eligible for interview, and one 
woman in each household was selected at random and interviewed by a trained interviewer. The national sample of women for the current study was 4,916. However, 65 of these were not de jure residents of the households where they were interviewed. Respondents who were de facto but not de jure residents are not included in the present study. Also studied were the sub-sample of all 530 respondents in the three northernmost rural regions and the sub-sample of all 853 respondents in urban Greater Accra.

\section{Study variables}

For the rest deprivation variable the respondents were asked 'How many hours do you rest a day, including naps and sleep both during the day and night (response frame 1-3 hours, 4-6 hours, 7-9 hours, 10 and more hours, don't know)? For this study, this variable was dichotomized into $\leq 6$ hours (rest deprivation) and $\geq 7$ hours (rest sufficiency). Hereafter the terms 'rest deprivation' and 'rest sufficiency' are used as labels for the two values of the binomial rest variable. For age, a variable with five-year categories was used. For wealth the DHS Wealth Index was used, which is constructed using a principle components analysis to score a household's quality and assets. For the GDHS 2008 these assets included ownership of consumer items such as television, bicycle, car, and also dwelling characteristics such as drinking water, sanitation facilities, and flooring material. Each household was given a wealth score, and this score was assigned to each individual within the household. The national sample was divided into quintiles from the richest to the poorest, and these quintiles were used in this study. The Wealth Index was recalculated for each sub-sample. Education was measured by a three-category variable (secondary or higher, primary, no education). To create the occupation variable, occupational categories from GDHS were dichotomized into 'white collar' (professional/technical/managerial, clerical, sales and services) and 'agriculture/labour' (agriculture self-employed, agriculture, skilled manual labour and unskilled manual labour, household/domestic labour).

In addition to education, occupation and wealth, other putative living conditions indicators were examined in this study. All of the assets that composed the Wealth Index were also separately evaluated for their relationship to the rest variable. The living conditions indicators included also land ownership and livestock ownership (both coded yes/no). For religion, the GDHS variable was recoded into a dichotomy of 'Christian' (Catholic, Anglican, Methodist, Pentecostal/Charismatic, other Christian) and 'Moslem/other' (Moslem, Traditionalist/ other, no religion). During interviews, literacy was tested with a reading card. Three categories were recoded into a dichotomy of 'can read' (able to read only parts of sentence, able to read whole sentence) or 'cannot read' (cannot read at all).

The data were weighted in this way: "There are two main sampling weights in DHS surveys: household weights and individual weights. The household weight for a particular household is the inverse of its household selection probability multiplied by the inverse of the household response rate of its household response rate group. The individual weight of a respondent's case is the household weight multiplied by the inverse of the individual response rate of her individual response rate group." [[27], page 12]

SPSS 15 was used for all analyses. The Chi-square test was used to test associations between rest deprivation and all the living conditions indicators. Binary logistic regression was used to compute odds ratios and 95\% confidence intervals, separately for all three samples, in analyses including all the living conditions indicators having a significant two-way relationship to the rest variable.

\section{Results \\ Respondents}

The 4,916 women survey respondents were distributed by age as follows: $15-19$ (20.8\%); 20-24 (17.9\%); 25-29 (16.9\%); 30-34 (13.1\%); 35-39 (13.0\%); 40-44 (9.6\%); $45-49(8.7 \%)$. The sample sizes from the ten regions ranged from a low of 334 in the Central region to a high of 815 in the Ashanti region. The weighted sample size ranged from 122 in the Upper West region to 1,011 in the Ashanti region. Sixty-five respondents were not resident in the households they were interviewed in and were excluded from all analyses. Excluding these de facto residents, missing data rates ranged from a low of $0.0 \%$ to a high of $1.7 \%$ for the variables included in this study. All analyses reported from this point forward were conducted with weighted data.

Prevalence's of rest deprivation were $13.0 \%$ nationally, 14.5\% in Greater Accra and 16.8\% in the North.

In national-level bivariate analyses, social indicators significantly related to the rest variable were age, education, wealth index, Christian religion and literacy (Table 1). In Greater Accra, the significant correlates were age, wealth index, having household electricity, and possession of a refrigerator, a modern cooking stove and a mobile phone (Table 2). In the North, the significant correlates were education, occupation, drinking water source, possession of a motorcycle/scooter, Christian religion, literacy, and having a wall clock and a cupboard (Table 3 ).

Intercorrelations for all study variables were examined and the data were examined for possible multicollinearity, but no evidence for that was found. In a binary logistic regression analysis using the national data and controlling for age, the significant $(\mathrm{p}<0.05)$ odds ratios 
Table 1 Rest variable by all social variables, national sample

\begin{tabular}{|c|c|c|c|c|}
\hline \multirow[t]{2}{*}{$\begin{array}{l}\text { Putative social } \\
\text { determinant indicators }\end{array}$} & \multicolumn{2}{|c|}{$\begin{array}{c}\text { Rest/naps/sleep } \\
(\%)\end{array}$} & \multirow[t]{2}{*}{$\begin{array}{c}\text { Number } \\
\text { (weighted) }\end{array}$} & \multirow[t]{2}{*}{$\chi^{2}$} \\
\hline & $\begin{array}{l}7 \text { or } \\
\text { more } \\
\text { hours }\end{array}$ & $\begin{array}{c}6 \text { or } \\
\text { less } \\
\text { hours }\end{array}$ & & \\
\hline Age group & & & & $p<0.000$ \\
\hline $15-19$ & 91.2 & 8.8 & 1,014 & \\
\hline $20-24$ & 90.7 & 9.3 & 873 & \\
\hline $25-29$ & 87.5 & 12.5 & 811 & \\
\hline $30-34$ & 83.0 & 17.0 & 636 & \\
\hline $35-39$ & 83.4 & 16.6 & 634 & \\
\hline $40-44$ & 84.2 & 15.8 & 463 & \\
\hline $45-49$ & 80.4 & 19.6 & 423 & \\
\hline Total & 86.8 & 13.2 & 4,854 & \\
\hline Education & & & & $p<0.000$ \\
\hline Secondary or higher & 88.4 & 11.6 & 2,870 & \\
\hline Primary & 87.4 & 12.6 & 982 & \\
\hline No education & 81.8 & 18.2 & 997 & \\
\hline Occupation & & & & $p<0.823$ \\
\hline White collar & 86.9 & 13.1 & 3,689 & \\
\hline Agriculture, labour & 86.6 & 13.4 & 1,116 & \\
\hline Wealth index & & & & $p<0.008$ \\
\hline Richest quintile & 84.8 & 15.2 & 1,133 & \\
\hline Richer quintile & 86.7 & 13.3 & 1,111 & \\
\hline Middle quintile & 87.5 & 12.5 & 974 & \\
\hline Poorer quintile & 90.0 & 10.0 & 884 & \\
\hline Poorest quintile & 85.4 & 14.6 & 752 & \\
\hline Christian & & & & $p<0.000$ \\
\hline No & 80.4 & 19.6 & 1,064 & \\
\hline Yes & 88.6 & 11.4 & 3,788 & \\
\hline Literacy & & & & $p<0.001$ \\
\hline Can read & 88.5 & 11.5 & 2,469 & \\
\hline Cannot read & 85.2 & 14.8 & 2,360 & \\
\hline
\end{tabular}

were 1.40 for no education compared to secondary and higher education, 0.78-0.43 for the four poorer wealth index quintiles compared to the richest quintile, and 0.55 for Christian religion compared to all others (Table 4). In the data from Greater Accra and controlling for age, the significant $(\mathrm{p}<0.05)$ odds ratios were 2.15 for the second richest wealth quintile compared to the richest quintile and 0.16 for possession of a mobile phone (Table 5). In the data from the North, the significant $(\mathrm{p}<0.05)$ odds ratios were 1.87 for having a protected compared to an unprotected water source, 0.49 for Christian religion compared to all others, and 0.41 for having a cupboard in the home (Table 6).

\section{Discussion}

This study examined national and urban/rural prevalence's of rest deprivation in samples of Ghanaian
Table 2 Rest variable by social variables, Greater Accra sample

\begin{tabular}{|c|c|c|c|}
\hline Correlates & Rest/naps/sleep (\%) & $\begin{array}{c}\text { Number } \\
\text { (weighted) }\end{array}$ & $\chi^{2}$ \\
\hline & $\begin{array}{cc}7 \text { or more } \\
\text { hours }\end{array} \begin{array}{c}6 \text { or less } \\
\text { hours }\end{array}$ & & \\
\hline
\end{tabular}

\begin{tabular}{lccc}
\hline Age group & & & \\
$15-19$ & 90.1 & 9.9 & 162 \\
$20-24$ & 89.6 & 10.4 & 173 \\
$25-29$ & 86.3 & 13.7 & 146 \\
$30-34$ & 79.3 & 20.7 & 135 \\
$35-39$ & 78.8 & 21.2 & 104 \\
$40-44$ & 87.0 & 13.0 & 77 \\
$45-49$ & 80.8 & 19.2 & 52 \\
Total & 85.4 & 14.6 & 849
\end{tabular}

\begin{tabular}{lcccc}
\hline $\begin{array}{l}\text { Education } \\
\text { Secondary or }\end{array}$ & 84.7 & 15.3 & 661 & \\
higher & & & & \\
Primary & 90.4 & 9.6 & 125 & \\
No education & 84.4 & 15.6 & 64 & \\
\hline $\begin{array}{l}\text { Occupation } \\
\text { White collar }\end{array}$ & 85.6 & 14.4 & 824 & \\
Agriculture, labour & 90.5 & 9.5 & 21 & \\
\hline Wealth index & 86.5 & 13.5 & 170 & $p<0.53$ \\
Richest quintile & 73.5 & 26.5 & 170 & \\
Richer quintile & 88.2 & 11.8 & 170 & \\
Middle quintile & 89.9 & 10.1 & 168 & \\
Poorer quintile & 89.5 & 10.5 & 172 & \\
Poorest quintile & & & & \\
\hline Electricity & & & & $p<0.02$ \\
Yes & 84.1 & 15.9 & 718 & \\
No & 92.7 & 7.3 & 123 & \\
\hline Refrigerator & & & & $p<0.01$ \\
Yes & 82.8 & 17.2 & 505 & \\
No & 89.5 & 10.5 & 333 & \\
\hline Cooking fuel & & & & \\
Elec., gas, & 85.0 & 15.0 & 811 & $\mathrm{p}<0.03$ \\
kerosene & 100.0 & 0.00 & 27 & \\
Wood, bush, grass & & & & \\
\hline Mobile phone & & & & \\
Yes & 84.2 & 15.8 & 759 & \\
No & 97.5 & 2.5 & 81 & \\
\hline & & & & \\
\hline
\end{tabular}

women, and the association of social indicators of living conditions with rest deprivation. Regarding the three prevalence estimates, ranging from $13 \%$ nationally to $16.8 \%$ in the North, the only somewhat comparable findings are from the USA's 2006 BRSS [21], in which the prevalence of rest deprivation was $25 \%$. However the exact measures used were different in the USA and the Ghana studies, and the Ghana measure suffers from not have a defined period, such that the period prevalence in not known. The BRSS measure has a period of the 
Table 3 Rest variable by all social variables, North sample

\begin{tabular}{|c|c|c|c|c|}
\hline \multirow[t]{2}{*}{ Correlates } & \multicolumn{2}{|c|}{ Rest/naps/sleep (\%) } & \multirow{2}{*}{$\begin{array}{c}\text { Number } \\
\text { (weighted) }\end{array}$} & \multirow[t]{2}{*}{$\chi^{2}$} \\
\hline & $\begin{array}{l}7 \text { or more } \\
\text { hours }\end{array}$ & $\begin{array}{c}6 \text { or less } \\
\text { hours }\end{array}$ & & \\
\hline Age group & & & & $p<0.27$ \\
\hline $15-19$ & 88.0 & 12.0 & 117 & \\
\hline $20-24$ & 86.3 & 13.7 & 73 & \\
\hline $25-29$ & 77.3 & 22.7 & 75 & \\
\hline $30-34$ & 78.0 & 22.0 & 59 & \\
\hline $35-39$ & 78.9 & 21.1 & 76 & \\
\hline $40-44$ & 88.7 & 11.3 & 53 & \\
\hline $45-49$ & 83.0 & 17.0 & 53 & \\
\hline Total & 83.2 & 16.8 & 506 & \\
\hline Education & & & & $p<0.001$ \\
\hline $\begin{array}{l}\text { Secondary or } \\
\text { higher }\end{array}$ & 94.7 & 5.3 & 75 & \\
\hline Primary & 89.9 & 10.2 & 98 & \\
\hline No education & 78.8 & 21.2 & 330 & \\
\hline Occupation & & & & $p<0.02$ \\
\hline White Collar & 88.0 & 12.0 & 208 & \\
\hline $\begin{array}{l}\text { Agriculture, } \\
\text { labour }\end{array}$ & 79.8 & 20.2 & 292 & \\
\hline Wealth index & & & & $p<0.39$ \\
\hline Richest quintile & 83.8 & 16.2 & 99 & \\
\hline Richer quintile & 77.6 & 22.4 & 98 & \\
\hline Middle quintile & 87.6 & 12.4 & 105 & \\
\hline Poorer quintile & 81.4 & 18.6 & 97 & \\
\hline Poorest quintile & 84.9 & 15.1 & 106 & \\
\hline \multicolumn{5}{|l|}{$\begin{array}{l}\text { Drinking water } \\
\text { source }\end{array}$} \\
\hline Protected & 86.5 & 13.5 & 421 & $p<0.000$ \\
\hline Unprotected & 67.1 & 32.9 & 82 & \\
\hline \multicolumn{5}{|l|}{$\begin{array}{l}\text { Motorcycle/ } \\
\text { scooter }\end{array}$} \\
\hline Yes & 73.3 & 26.7 & 75 & $p<0.02$ \\
\hline No & 84.8 & 15.2 & 428 & \\
\hline \multicolumn{5}{|l|}{ Christian } \\
\hline No & 76.4 & 23.6 & 288 & $p<0.000$ \\
\hline Yes & 92.1 & 7.9 & 216 & \\
\hline \multicolumn{5}{|l|}{ Literacy } \\
\hline Can read & 94.8 & 5.2 & 96 & $p<0.001$ \\
\hline Cannot read & 80.6 & 19.4 & 407 & \\
\hline \multicolumn{5}{|l|}{ Wall clock } \\
\hline Yes & 73.5 & 26.5 & 98 & $p<0.004$ \\
\hline No & 85.6 & 14.4 & 404 & \\
\hline Cupboard & & & & $p<0.000$ \\
\hline Yes & 63.2 & 36.8 & 76 & \\
\hline No & 86.9 & 13.1 & 427 & \\
\hline
\end{tabular}

Table 4 Odd Ratios (OR) and 95\% Confidence intervals (CI) for reporting rest deprivation amongst Ghanaian women, national sample

\begin{tabular}{lll}
\hline Selected predictors & OR & $\mathbf{9 5 \%} \mathbf{C l}$ \\
\hline Age group & 1 & \\
$15-19$ (ref.) & 0.99 & $1.03-1-92$ \\
$20-24$ & $1.41^{*}$ & $1.37-2.58$ \\
$25-29$ & $1.88^{* *}$ & $1.39-2.62$ \\
$30-34$ & $1.91^{* *}$ & $1.29-2.58$ \\
$35-39$ & $1.83^{* *}$ & $1.64-3.24$ \\
$40-44$ & $2.31^{* *}$ & \\
$45-49$ & & \\
\hline
\end{tabular}

\section{Education}

Secondary \& higher (ref)

\begin{tabular}{lll} 
Primary & 1.11 & $0.84-1.45$ \\
No Education & $1.40^{*}$ & $1.03-1.89$ \\
\hline Wealth index & & \\
Richest quintile (ref.) & 1 & \\
Richer quintile & $0.78^{*}$ & $0.61-1.00$ \\
Middle quintile & $0.71^{*}$ & $0.54-0.92$ \\
Poorer quintile & $0.52^{* *}$ & $0.39-0.80$ \\
Poorest quintile & $0.43^{*}$ & $0.43-0.80$
\end{tabular}

\begin{tabular}{lll}
\hline Christian & & \\
No (ref.) & 1 & $0.45-0.67$ \\
Yes & $0.55^{* *}$ & \\
\hline
\end{tabular}

Yes

\section{Literacy}

$\begin{array}{lll}\text { Can read (ref.) } & 1 & 0.78-1.29\end{array}$

Cannot read $\quad 1.00$

\begin{tabular}{lc}
\hline $\mathbf{- 2}$ Log likelihood & $3,625.03$ \\
\hline Cox \& Snell R Square & 0.026 \\
\hline
\end{tabular}

Note ${ }^{*}$ Significant at $\mathrm{p}<0.05$,

${ }^{* *} p<0.001$, ref $=$ reference category

past 14 days. In the Ghana data collection interview, the question immediately prior to the rest question was about physical activity and had a response frame of the last seven days. If this response frame remained salient when the rest question was posed, then the period of the prevalence estimate is one week, half that of the period in the BRSS study. However, this is merely conjecture, and illustrates the need for survey research to be very clear about the reporting period when collecting data on past behaviour/experience. Research is also needed on the validity of self-report measures of rest pattern, and it is a limitation of this study that the validity of the rest measure has not been ascertained.

In the regression analysis with the national data, age was a risk indicator at age category 25-29 (and all the older categories), compared to age category 15-19. 
Table 5 Odd Ratios (OR) and $95 \%$ Confidence intervals (CI) for reporting rest deprivation, Greater Accra sample

\begin{tabular}{lll}
\hline Selected predictors & OR & $\mathbf{9 5 \%} \mathbf{C l}$ \\
\hline Age group & & \\
$15-19$ (ref.) & 1 & $0.47-2.04$ \\
$20-24$ & 0.98 & $0.66-2.74$ \\
$25-29$ & 1.34 & $1.01-4.03$ \\
$30-34$ & $2.02^{*}$ & $1.24-5.12$ \\
$35-39$ & $2.54^{*}$ & $0.49-2.74$ \\
$40-44$ & 1.16 & $0.95-5.52$ \\
$45-49$ & 2.28 & \\
\hline
\end{tabular}

\section{Wealth index}

Richest quintile (ref.)

Richer quintile

Middle quintile

Poorer quintile

Poorest quintile

Household has electricity

\begin{tabular}{lll} 
Yes (ref.) & 1 & $0.31-1.56$ \\
No & 0.70 & \\
\hline
\end{tabular}

\section{Household has refrigerator}

\begin{tabular}{lll} 
Yes (ref.) & 1 & $0.44-1.54$ \\
No & 0.83 & \\
\hline
\end{tabular}

\section{Cooking fuel}

Elec., gas, kerosene (ref.).

Wood, bush, grass, etc

Household has mobile phone

\begin{tabular}{lcc} 
Yes (ref.) & 1 & $0.04-0.72$ \\
No & $0.16^{*}$ & \\
\hline $\mathbf{- 2}$ Log likelihood & 643.43 \\
\hline R Square, Cox \& Snell/Nagelkirke & $0.06 / 0.11$ \\
\hline
\end{tabular}

Note * Significant at $p<0.05$, ref $=$ reference category

In the Greater Accra data, age was a risk indicator at age 30-34 and higher, compared to the age category 1519. In the North analysis, age was not a risk indicator. This is not due to differences in the distributions of age; the largest age distribution difference was 5.3 percent for 35-39 years olds. We conclude that for unknown reasons, the rest variable did not vary significantly with age in the North, while it did vary significantly with age in the national sample and in Greater Accra. This is evidence for a position that generalisation from national contexts to regional contexts should only be done when there is an empirical basis to do so.

Similarly, education was significantly associated with the rest variable in national data but not in regional data. Unlike age, there was a large difference in the distribution of education categories by region; the proportion reporting secondary or higher education versus no education was $59 \%$ versus $21 \%$ in the national sample, $78 \%$ versus $8 \%$ in Greater Accra and $15 \%$ versus $65 \%$ in the North. Thus, the two regions exhibit great
Table 6 Odd Ratios (OR) and 95\% Confidence intervals (CI) for reporting rest deprivation, North sample

\begin{tabular}{lll}
\hline Selected predictors & OR & 95\% Cl \\
\hline Education & 1 & $0.23-8.73$ \\
Secondary or higher (ref.) & 1.43 & $0.28-13.37$ \\
Primary & 1.95 & \\
No education & & \\
\hline Occupation & 1 & $0.70-2.26$ \\
White collar (ref.) & 1.26 & \\
Agriculture, labour & & \\
\hline Water source & 1 & $1.04-3.38$ \\
Protected (ref.) & $1.87^{*}$ & \\
Unprotected & & \\
\hline Household has motorcycle/scooter & 1 & $0.37-1.32$ \\
Yes (ref.) & 0.69 & \\
No & & \\
\hline Christian & 1 & $0.26-0.92$ \\
No (ref) & $0.49^{*}$ & \\
Yes & & \\
\hline Literacy & 1 & $0.34-10.37$ \\
Can read (ref.) & 1.86 & \\
Cannot read & & \\
\hline Household has wall clock & 1 & $0.30-1.04$ \\
Yes (ref.) & 0.56 & \\
No & & \\
\hline Household has cupboard & & \\
Yes (ref.) & & \\
No & & \\
\hline $\mathbf{- 2}$ Log likelihood & & \\
\hline R Square, Cox \& Snell/Nagelkerke & & \\
\hline Note Sign & & \\
\hline
\end{tabular}

Note * Significant at $\mathrm{p}<0.05$, ref $=$ reference category

heterogeneity on this indicator of living conditions and this in itself is a caution against generalisation of findings from one region to another, or of national findings to regions.

The Wealth Index was significantly related to the rest variable in the national sample, but not in the two regional samples. As for education, there were very large differences in the distribution of the Wealth Index by region. In Greater Accra, using Wealth Index scores generated with the national data, $63.8 \%$ were in the richest quintile compared to 6.7 percent in the North. In Greater Accra, 0.3\% was in the poorest quintile compared to $54.7 \%$ in the North. In Greater Accra, also using national Wealth Index scores, the two richest quintiles accounted for $90.5 \%$ of all respondents. In the North, the two poorest quintiles accounted for $72.1 \%$ of all respondents. This 'truncation' of the range of wealth is noteworthy, but national wealth scores were not used in this study. Rather, the Wealth Index was recalculated separately for the Greater Accra and the North samples, 
such that the quintiles were of approximately equal size in all three analyses, about $20 \%$ each. Still, one might argue that the concentrations of relative wealth in Greater Accra and poverty in the North reduce variability to such an extent that wealth is not sufficiently variable to be considered as a living conditions indicator. We agree about this possibility, but entertain also another possibility. There is debate in the literature on the social determinants of health about the significance of absolute versus relative levels of living condition indicators. Some argue that absolute levels are of greatest relevance because absolute poverty under certain levels produces conditions for poor health [28]. Others argue that relative levels must also be relevant, since the social gradient in health is evident all along the income spectrum [29]. Illustrating this with the absurd, a man well enough off to own a single engine airplane may be sick with envy because all the neighbours own two engine planes. This is an argument that social position, perhaps alongside wealth, is a determinant of health, and perhaps even more so in very poor societies where education, paid occupation and wealth are relatively scarce. Further, it may be that the social indicators of social position are different in relatively wealthy compared to relatively poor places, such that education, occupation and wealth are most relevant in wealthier places, but not so relevant in poorer places.

This study certainly presents evidence in line with the above reasoning. These exploratory findings suggest that national/international findings from research on the social determinants of health should be generalised to regions only with great caution, if at all. Moving to the heart of the issue, health is variable in poor places as well as wealthy places, and in urban and well as rural areas, as the rest variable data in this paper illustrates. Health in any place is not distributed randomly. Therefore, there exist determinants of health, amongst which there will likely be social determinants. For research on the social determinants of health in very poor regions, a main task is to search for those social determinants, when the classical social determinants are observed to have little explanatory power. Poor regions may be urban or rural, so these issues are equally relevant in both types of places. The result of the above line of reasoning is a call for qualitative, exploratory research in very poor regions in the Global South, to illuminate how living conditions, social position, culture, and health and welfare infrastructure/services affects health.

Moving to other issues, the finding that belonging to a Christian faith (in the national sample and the North sample) is protective against rest deprivation deserves some comment. Belonging to a Christian faith has previously been found to be related to improved health outcomes in Ghana. Women who reported being Christian had higher knowledge of AIDS than women reporting being Moslem or Traditionalist [30]. Also in Ghana, being Christian as opposed to Moslem or Traditionalist was found to predict maternal health service utilization after controlling for the socio-economic variables education and household wealth [31]. The patriarchal culture of Ghana, especially in the North, leaves women with heavy workloads combining livelihood generation and domestic chores with giving birth to and taking care of children, a burden which has been reported to influence several health aspects including sleep [32,33]. Christian culture might moderate the degree of patriarchy in the northern rural areas, thereby to some degree reducing the strain of everyday living for women. In qualitative research by the second author in northern Ghana [34], support for such an effect was observed. Christian culture led to an increased support from husbands to their wives, practically as well as emotionally. The combined effect of religion-related cultural differences might be a reduction of the total life strain for Christian women, leading to increased time for rest. Data on religious affiliations other than the Christian faiths were available, including affiliation with Moslem and traditional faiths. In preliminary analyses, affiliation with either of these was a risk indicator for rest deprivation. This was not pursued as a main point in this paper due the complexity of understanding how cultural indicators such as religious faith are factors in health studies. We wished to avoid the possibility of stigmatisation and chose instead to focus on the protective relationship that Christian faith has with rest deprivation.

The usual measure of wealth is the one used in this study, the Wealth Index. However we also examined possible 'sentinel' possessions, and found that possession of a mobile phone is protective in Greater Accra but not in the North, with the opposite being true for ownership of a cupboard in the North. Individual possessions were included in the analyses in this study in a search for 'sentinel' indicators of social position, that could be used in future survey research if reliably associated with health measures. In this study, neither of these candidate sentinel possessions was reliably associated with rest in multivariate analyses, even if they (and many other candidate sentinel possessions) were significant in bivariate analyses. We conclude that the idea of sentinel wealth indicators may be worth following, but not as a high priority.

Regarding rest deprivation/sufficiency, we know that in Ghana, rest deprivation is highly prevalent, and we may assume that it has significance for health, not from present findings but from the large literature showing that adequate rest and sleep are vital to good health. Further research on rest deprivation is therefore called for; it is to be hoped that the lead of the 2006 BRSS and 
the 2008 GDHS will be followed by others doing health survey research in the Global South. However, consensus is urgently needed on standardised measurement and reporting periods for prevalence estimates. It may be most prudent to use the 2006 BRSS measure, for which substantial US data are available, and whose twoweek period prevalence seems to be a reasonable recall period.

The differing sample sizes are problematic. Power increases with sample size, making it easier to achieve significance in larger than smaller samples, even for effects of similar size. This is well illustrated in the analyses on the predictive power of education on sleep deprivation in the largest and smallest samples (Tables 4 and 6): an OR of 1.40 reaches significances in the national sample, while an OR of 1.95 fails to reach significance in the North. It is reasonable to conclude that this is due to sample size differences. The results from this study should therefore be interpreted with care, especially for analyses comparing national and regional levels. Comparisons between the two regional samples (Greater Accra versus North), can be done with a higher degree of confidence, as the sample sizes are far more similar. In the bivariate analyses for these two regions, no variables emerged as being significant in both samples. This supports the conclusion that caution should be taken when generalizing from findings in one region to another region within a country.

The study is cross-sectional and all the usual caveats about cross-sectional data apply. More importantly, the rest variable is crude, and many important aspects of rest are unmeasured, not least, quality of rest, and proportions of rest from relaxation, naps and sleep. It is laudatory that the 2008 GDHS included an item on rest, but one could have hoped for a few more items as well. Regarding the failure to find an expected relationship between occupation and rest, this may be due to a too crude dichotomisation of the large number of occupations that were classified as white collar or agriculture and labour. Accordingly, we plan to study the associations of occupation and rest in detail, to determine if there is a more sensible way to classify occupation in studies of rest sufficiency. Regarding education, it is quite likely not sufficient to measure only formal education in places were many people have none, as in Northern Ghana. Education for life skills is informal for many people in the world, passed down from generation to generation within families, from elders to the youth in villages, and from artisans to apprentices in communities everywhere. Further work is needed to develop measures for survey research that are sensitive enough to measure levels of informal education, to measure life skills, and to measure social position with validity and reliability.

\section{Conclusions}

Education, occupation and wealth are not related to patterns of rest in two regions of Ghana, even if education and wealth are related to rest patterns in national level data. This study did not illuminate social determinants of rest patterns at regional level, while it did observe that findings at the national level do not generalise to the regional level. Caution is advised in generalising from national data to regions as far as rest patterns are concerned. It is open to further investigation to determine if restricted generalisability is an issue in other countries and for other health endpoints.

We conclude with a point of substantial importance; the social indicators that were examined in this study accounted for very little variance in the rest variable, which is clear from the model fit data in Tables 4, 5 and 6. As mentioned already, we assume that rest patterns do have social determinants, but none of substantial significance was evident among the social variables available in this study. We are convinced that qualitative research in local contexts is needed in order to illuminate the social determinants of rest pattern, and to provide guidance about better ways to measure such determinants in future survey research.

\section{Acknowledgements}

The authors acknowledge the financial support of the Department of Health of England (DHE), which funded the research programme The Social Determinants of Health in Very Poor Ruralities, of which this study is a part. We express gratitude to Maggie Davies and Christopher Brookes of the DHE, who participated actively in the discussions that launched this work and without whose support this paper could not have been completed. The authors acknowledge also the International Union for Health Promotion and Education and its Working Group on the Social Determinants of Health, to which this study is a contributor. The authors acknowledge especially the researchers, participants and sponsors of the 2008 Ghana Demographic and Health Survey, including the Ghana Statistical Service of the Ghana Health Service, the Ghana AIDS Commission, ICF Macro (Calverton, Maryland, USA), USAID, INICEF, UNFPA and the Danish International Development Agency.

\section{Authors' contributions}

TB conceived of the study, MBM did the final statistical analyses and wrote the first draft of this paper. MB and TB did preliminary analyses. MBM and TB interpreted the results and contributed to later drafts. Both authors read and approved the final manuscript.

\section{Competing interests}

The authors declare that no competing interests exist.

Received: 19 January 2010 Accepted: 28 September 2010

Published: 28 September 2010

\section{References}

1. Hall MH, Muldoon MF, Jennings JR, Buysse DJ, Flory JD, Manuck SB: SelfReported Sleep Duration is Associated with the Metabolic Syndrome in Midlife Adults. Sleep 2008, 31(5):635-643.

2. Meisinger $C$, Heier $M$, Löwel H, Schneider A, Döring A: Sleep Duration and Sleep Complaints and Risk of Myocardial Infarction in Middle-aged Men and Women from the General Population: The MONICA/KORA Augsburg Cohort Study. Sleep 2007, 30(9):1121-1127. 
3. Grandner MA: Self-reported Sleep Complaints With Long and Short Sleep: A Nationally Representative Sample. Psychosomatic Medicine 2004 66:239-241.

4. Cappuccio FP, Taggart FM, Kandala N, Currie A, Peile E, Stranges S, Miller MA: Meta-Analysis of Short Sleep Duration and Obesity in Children and Adults. Sleep 2008, 31(5):619-626.

5. Gangwisch JE, Heymsfield SB, Boden-Albala B, Buijs RM, Kreier F, Pickering TG, Rundle AG, Zammit GK, Malaspina D: Short Sleep Duration as a Risk Factor for Hypertension: Analyses of the First National Health and Nutrition Examination Survey. Hypertension 2006, 47(5):833-839.

6. Kaneita Y, Uchiyama M, Yoshiike N, Ohida T: Associations of Usual Sleep Duration with Serum Lipid and Lipoprotein Levels. Sleep 2008, 31(5):645-652.

7. Miller MA, Kandala N, Kivimaki M, Kumari M, Brunner EJ, Lowe GDO, Marmot MG, Cappuccio FP: Gender differences in the cross-sectional relationships between sleep duration and markers of inflammation: Whitehall II study. Sleep 2009, 32(7):857-864.

8. Patel SR, Ayas NT, Malhotra MR, White DP, Schernhammer ES, Speizer FE, Stampfer MJ, Hu FB: A prospective study of sleep duration and mortality risk in women. Sleep 2004, 27(3):440-444.

9. Stamatakis KA, Kaplan GA, Roberts RE: Short Sleep Duration Across Income, Education, and Race/Ethnic Groups: Population Prevalence and Growing Disparities During 34 Years of Follow-Up. Annals of Epidemiology 2007, 17(12):948-955

10. Tanaka H, Shirakawa S: Sleep health, lifestyle and mental health in the Japanese elderly ensuring sleep to promote a healthy brain and mind. Journal of psychosomatic research 2004, 56(5):465-477.

11. Moldofsky H, Lue FA, Davidson JR, Gorczynski R: Effects of sleep deprivation on human immune functions. The FASEB Journal 1989, 3:1972-1977

12. Irwin M, Clark C, Kennedy B, Christian Gillin J, Ziegler M: Nocturnal catecholamines and immune function in insomniacs, depressed patients, and control subjects. Brain Behavior and Immunity 2003, 17(5):365-372.

13. Groeger JA, Zijlstra FRH, Dijk DJ: Sleep quantity, sleep difficulties and their perceived consequences in a representative sample of some 2000 British adults. Journal of Sleep Research 2004, 13(4):359-371.

14. Strine TW, Chapman DP: Associations of frequent sleep insufficiency with health-related quality of life and health behaviors. Sleep Medicine 2005, 6(1):23-27.

15. Jean-Louis G, Kripke DF, Ancoli-Israel S: Sleep and Quality of Well-Being. Sleep 2000, 23(8):1-7.

16. Kripke DF, Garfinkel L, Wingard DL, Klauber MR, Marler MR: Mortality Associated With Sleep Duration and Insomnia. Arch Gen Psychiatry 2002, 59(2):131-136, Reprint 2010

17. He J, Kryger M, Zorick F, Conway W, Roth T: Mortality and apnea index in obstructive sleep apnea. Experience in 385 male patients. Chest 1988, 94(1):9-14

18. Soldatos CR, Dikeos DG, Paparrigopoulos TJ: The diagnostic validity of the Athens Insomnia Scale. Journal of psychosomatic research 2003, 55(3):263-267.

19. Soldatos CR, Allaert FA, Ohta T, Dikeos DG: How do individuals sleep around the world? Results from a single-day survey in ten countries. Sleep Medicine 2005, 6(1):5-13.

20. Biddle JE, Hamermesh DS: Sleep and the Allocation of Time. The Journal of Political Economy 1990, 98(5):922-943.

21. McKnight-Eily LR, Presley-Cantrell LR, Strine TW, Chapman DP, Perry GS, Croft JB: Perceived insufficient rest or sleep-four states, 2006. MMWR Morb Mortal Wkly Rep 2008, 57:200-203.

22. $\mathrm{WHO} C \mathrm{CSDH}$ : Closing the gap in a generation: health equity through action on the social determinants of health. Final Report of the Commission on Social Determinants of Health. Geneva 2008.

23. Bull T: Social determinants of health in very poor ruralities. Global Health Promotion 2009, 16(1):53-56.

24. Ghana Statistical Service (GSS), Ghana Health Service (GHS), and ICF Macro. 2009: Ghana Demographic and Health Survey 2008. Accra, Ghana 2009.

25. UNDP Human Development Ranking. 2009 [http://hdr.undp.org/en/ statistics/].

26. WHO Country briefs on Ghana. [http://www.who.int/countries/gha/gha/ en/].

27. Rutstein SO, Rojas G: Guide to DHS Statistics. Demographic and Health Surveys, ORC Macro, Calverton, Maryland 2006.
28. Lynch JW, Smith GD, Kaplan GA, House JS: Income inequality and mortality: importance to health of individual income, psychosocial environment, or material conditions. British Medical Journal 2000, 320:1200-1204

29. Marmot MG: Understanding Social Inequalities in Health. Perspectives in Biology and Medicine 2003, 46(3):9-23.

30. Takyi B: Religion and Women's Health in Ghana: Insights into HIV/AIDS Preventive and Protective Behavior. Social Science \& Medicine 2003 56(6):1221-35.

31. Gyimah SO, Takyi BK, Addai I: Challenges to the reproductive-health needs of African women: On religion and maternal health utilization in Ghana. Social Science \& Medicine 2006, 62(12):2930-2944.

32. Avotri JY, Walters V: You just look at our work and see if you have any freedom on earth": Ghanaian women's accounts of their work and their health. Social Science \& Medicine 1999, 48(9):1123-1133

33. Avotri JY, Walters V: 'We Women Worry a Lot About Our Husbands': Ghanaian women talking about their health and their relationships with men. Journal of Gender Studies 2001, 10(2):197-211.

34. Bull T: The Ghana field visit, April 2009. In Living conditions and determinants of social position amongst women of child-bearing age in very poor ruralities: qualitative exploratory studies in India, Ghana and Haiti. IUHPE Research Report Series Edited by: Bull T, Mittelmark MB 2010, V(1):82-122.

\section{Pre-publication history}

The pre-publication history for this paper can be accessed here: http://www.biomedcentral.com/1471-2458/10/580/prepub

doi:10.1186/1471-2458-10-580

Cite this article as: Mittelmark and Bull: Social determinants of rest deprivation amongst Ghanaian women: national and urban-rural comparisons with data from a cross-sectional nationally representative survey. BMC Public Health 2010 10:580.

\section{Submit your next manuscript to BioMed Central and take full advantage of:}

- Convenient online submission

- Thorough peer review

- No space constraints or color figure charges

- Immediate publication on acceptance

- Inclusion in PubMed, CAS, Scopus and Google Scholar

- Research which is freely available for redistribution
Biomed Central 